\title{
THE DEVELOPMENT OF TEMPERAMENT EVALUATION OF MEMPHIS, PISA, PARIS, AND SAN DIEGO - AUTO-QUESTIONNAIRE FOR ADOLESCENTS (A-TEMPS-A) IN A SERBIAN SAMPLE
}

\author{
Jelena Jović ${ }^{1}$, Darko Hinić ${ }^{2}$, Aleksandar Ćorac ${ }^{1}$, Hagop S. Akiskal ${ }^{3}$, Kareen Akiskal ${ }^{3}$, \\ Icro Maremmani ${ }^{4}$, Dina Popović ${ }^{5}$ \& Dragana Ristić-Ignjatović ${ }^{6}$ \\ ${ }^{l}$ Department of Preventive Medicine, School of Medicine, University of Prishtina - Kosovska Mitrovica, Serbia \\ ${ }^{2}$ Faculty of Science, Faculty of Philology and Arts, University of Kragujevac, Serbia \\ ${ }^{3}$ International Mood Disorders Center, University of California, San Diego, USA \\ ${ }^{4}$ Department of Psychiatry, Santa Chiara University Hospital, University of Pisa, Italy \& “G. De Lisio”, \\ Institute of Behavioral Sciences, Pisa, Italy \\ ${ }^{5}$ Department of Psychiatry, Sheba Medical Center, Tel Aviv, Israel \& Bipolar Disorders Program, \\ Hospital Clinic, Barcelona, Spain \\ ${ }^{6}$ Faculty of Medical Sciences, University of Kragujevac, Kragujevac, Serbia
}

received: 10.7.2018;

revised: 26.11.2018;

accepted: 4.4.2019

\section{SUMMARY}

Background: Previous studies suggest that temperament features of adolescents may be good predictors of the development of future psychopathology in this population. The aim of the study was to adapt the content and validate the psychometric properties of the Temperament Evaluation of Memphis, Pisa, Paris, and San Diego - Auto-questionnaire in a sample of Serbian adolescents.

Subjects and methods: The sample included 2113 adolescents, $56 \%$ girls and 44\% boys, average age 16.73 \pm 0.47 , attending 48 Serbian secondary schools. The base for the development of this scale included Serbian standardised versions as well as the TEMPSI, Interview version.

Results: The final scale is comprised of 36 items, with six factors (depressive, cyclothymic, hyperthymic, irritable, and anxiouscognitive/somatic) explaining $39.9 \%$ of the total variance, the internal consistency coefficient $\alpha=0.77$, and the average test-retest coefficient (rho=0.84). The correlations among the temperaments ranged from weak to moderate, with the highest positive correlations between the depressive, cyclothymic and anxious scales. The highest values were detected on hyperthymic and the lowest on depressive temperament. Significantly higher scores of depressive, cyclothymic and anxious temperaments were detected in girls, whereas boys had higher scores on the hyperthymic scale.

Conclusions: The scale has shown good psychometric properties, which encourages its further use in adolescent population. The results show certain specific features of this population, such as higher scores on all temperament types than the ones in student and adult population and a tendency of socially desirable answers.

Key words: adolescent population - psychometric properties - temperament - TEMPS-A

$$
* * * * *
$$

\section{INTRODUCTION}

The period of adolescence is an intermediate stage between childhood and adulthood, when individuals intensively develop both physically and on a socioemotional plane, which makes this population a unique group with specific cognitive, emotional and social characteristics. Yet, adolescents are insufficiently presented in national health statistics, and represent a population that health care providers are not routinely trained to serve (WHO 2015).

The terms personality and temperament are frequently used interchangeably or even synonymously in the literature. Nevertheless, such levelling-up of the two concepts is unjustified because personality is the super ordinate concept, representing a relatively stable organisation of an individual and encompassing temperament (emotional responses), intelligence, moral and volitional elements (Ristić-Ignjatović 2011). Temperament refers to innate aspects of personality, which by definition constitute a firm and biologically determined base of emotional responses that is displayed from a relatively early age and remains fairly stable throughout one's life, indirectly defining both the cognitive aspect of personality and the activity level of an individual (Akiskal \& Akiskal 2005).

Investigating temperament types in adolescents is a particularly important field of research because temperament has a prominent role in psychosocial personality development. Many studies have indicated a relationship between extreme markedness of different temperamental traits and emotional/behavioural problems in adolescents through increased vulnerability to certain psychopathological disorders or other people's responses to these specific temperament expressions (Masi et al. 2003). 
Studies have suggested that certain affective temperament types are considerably important for occurrence, course and development of symptoms of some affective disorders, such as depression, bipolar disorder and anxiety (Tanabe et al. 2016, Maremmani et al. 2011, Tavormina 2010, Rihmer et al. 2010, Schuch 2009, Signoretta et al. 2005, Kochman et al. 2005, Masi et al. 2003), but that they also have a strong connection with suicidal behaviour (Baldessarini et al. 2016, Skala et al. 2012, Pompili et al. 2008). Moreover, if temperament is a risk factor for mood disorders, it may be activated or amplified by the complex psychosocial and biological changes associated with puberty and the transition to adolescence (Nolen-Hoeksema 2002).

In the light of such findings, determining types of temperament in adolescents could provide us with opportunity to detect potential risks for the development of a mental illness at early stages, and consequently to intervene promptly.

Temperament Evaluation of Memphis, Pisa, Paris, and San Diego - Auto-questionnaire - TEMPS-A, has been validated throughout the world and proven to be a valuable tool, not only for describing emotional reactivity and affective traits which are the fundamental predisposition underlying mood and affective disorders (Akiskal \& Akiskal 2005), but also certain forms of positive reactions in general population (Kesebir et al. 2013), as well as creativity and professional preferences (Rovai et al. 2013, Vellante et al. 2011). The scale assesses five temperament types: cyclothymic temperament, which relates to mood swings and emotional shifts, depressive, which relates to prevailing feelings of sadness, lethargy, apathy and pessimism, hyperthymic which includes increased activity and energy, positive mood, self-confidence and enthusiasm, while irritable temperament includes aggressive and impulsive reactions, fretfulness and bad-temperedness. In our previous studies (Ristić-Ignjatović et al. 2014, Hinić et al. 2013), anxious factor was divided into anxiouscognitive, which refers to cognitive manifestations of apprehension and uneasiness, and anxious-somatic, with somatic manifestations in headaches, stomachache and cardiovascular problems.

Although widely used, only a few studies to date have administred this scale on adolescents. Consequently, there is an evident need for an instrument measuring temperament types, adapted to adolescent population, which certainly differs from other populations, not only in its developmental characteristics, but also their lexicon, frame of reference and similar factors influencing comprehension of the scale content and items.

\section{Aim of the study \\ The aim of this study was to validate the psycho- metric properties and factor structure of the TEMPS-A in a large sample of adolescents.}

\section{SUBJECT AND METHODS}

In Serbia, primary education is compulsory and it lasts eight years. Secondary education includes grammar schools or vocational secondary schools (eg medical, technical, etc), which last four years and are attended by adolescents aged 15-18.

Based on the data from the Ministry of Education and Science of the Republic of Serbia (MPNTR 2015), at the time of research 462 secondary schools operated in the country territory. Firstly, we determined the geographic distribution of the schools in the sample based on the number of schools in the five official regions of Serbia (SORS 2015). Secondly, we determined their distribution according to the school type (grammar, vocational secondary schools). Having formed the quotas of the strata, we randomly selected 48 schools from the list of schools (i.e. $10 \%$ of all schools in total). In the schools themselves, we also randomly chose the concrete classes to take part in the research.

The participation in the study was voluntary, anonymous, and the informed consent was provided in written form. The approval was obtained by the Ethical Committee, University of Pristina, with temporary residence in Kosovska Mitrovica.

Due to the specific nature of adolescent population, trained administrators (trained psychologists as well as student teachers) were present during the questionnairetaking time, with an aim to help the subjects with potential uncertainties regarding the content of the items.

\section{Participants}

The final sample included 2113 adolescents, out of 2239 initially surveyed, 56\% females and 44\% males, with the mean age of $\mathrm{M}=16.73 ; \mathrm{SD}=0.47$. Detailed data concerning sociodemographic characteristics of the sample are shown in Table 1.

Table 1. Demographic characteristics of the sample

\begin{tabular}{lclrlrlr}
\hline Region & $\%$ & School Type & $\%$ & Average overall marks & $\%$ & Economic status & $\%$ \\
\hline Belgrade & 14.3 & grammar & 38.4 & excellent & 38.1 & low & 5.9 \\
Vojvodina & 20.6 & technical & 24.1 & very good & 37.2 & lower middle & 10.6 \\
Central \& West Serbia & 23.3 & economics & 17.1 & good & 22.6 & middle & 39.5 \\
South \& East Serbia & 32.3 & medical & 14.4 & satisfactory & 2.0 & upper middle & 27.2 \\
Kosovo \& Metohia & 9.4 & other & 6.0 & & & high & 16.9 \\
\hline
\end{tabular}


The number of girls is significantly higher in grammar schools $\left(\chi^{2}=39.02 ; \mathrm{p}<0.001\right)$, medical schools $\left(\chi^{2}=70.85 ; \quad \mathrm{p}<0.001\right)$ and schools of economics $\left(\chi^{2}=29.88 ; \mathrm{p}<0.001\right)$, while boys outnumbered girls in technical schools $\left(\chi^{2}=114.14 ; \mathrm{p}<0.001\right)$; hence this variable will be controlled in certain analyses.

\section{Measures}

All the participants filled in a brief sociodemographic questionnaire (age, sex, region, school type, average overall school marks, economic status), and the Adolescent Temperament Evaluation of Memphis, Pisa, Paris, and San Diego - Auto-questionnaire (ATEMPS-A).

The following scales served as a basis for the development of this version of the scale: Serbian standardised version of TEMPS-A for adult population (Ristić-Ignjatović et al. 2014), TEMPS-A version for university student population (Hinić et al. 2013), and the TEMPS-I, Interview version (Placidi et al. 1998a), which was employed in an Italian study for a sample mainly consisting of adolescents and administered in an interview format. The TEMPS-I was translated into the Serbian language by a certified translator. One more study was analysed, with the sample including adolescents (Guerreiro et al. 2013), wherein the TEMPS-A scale was also used. The accuracy of the final A-TEMPS-A translation was verified by one of the original authors of the scale (Akiskal H.S.). The internal consistency of the scale in Serbian university student population was $\alpha=0.77$ (Hinić et al. 2013), in adult $\alpha=0.83$ (Ristić et al. 2014), with the average testretest coefficient $(\mathrm{rho}=0.82)$ in both studies.

By means of analysing the existing items of the abovementioned scales, the overlapping items were deleted, as well as those inappropriate for adolescent population as regards their content. The final version of the scale, with 81 items, classified under five original temperament types: depressive (eg I often feel sad and unhappy), cyclothymic (eg My mood often changes for no reason), hyperthymic (eg I'm always on the move), irritable, (eg People say I burst for no reason), and anxious (eg I worry about usual daily things others consider minor). The subjects responded to yes/no statements, depending on whether they were applicable to them or not.

\section{Statistical Analyses}

The scores of each temperament subscale were represented by mean values, the total sums divided by the number of appropriate items. The normal distribution of the variables was verified with the Kolmogorov-Smirnov test, retest reliability with Spearman's coefficient and the reliability of the subscales was measured by Cronbach's alpha coefficient. Since the scores were not normally distributed, differences in scores were com- puted by the Mann-Whitney and Kruskal-Wallis tests, while the Spearman's coefficient was used for correlations. Confirmatory factor analysis (Maximum likelihood method) was also employed, in Amos 18. For the purposes of data analysis, SPSS for Windows 18 was used.

\section{RESULTS}

\section{Factorial structure of the A-TEMPS-A}

Besides items with weak initial extraction loadings $(<0.20)$, items that were problematic for the participants during the testing time (the ones they refused to answer or failed to understand the meaning of their content due to age and language barriers) were also excluded from the scale (eg I am driven by unpleasant restlessness that I don't understand). The scale included only items with $>0.40$ factor loadings, while those with negative loadings were excluded. The scale has shown good preliminary results that justified further factor analysis (Bartlett's test of sphericity $\chi^{2}(630)=13647.42 ; p<0.01$; $\mathrm{KMO}=0.89$ ).

Subsequently, confirmatory factor analysis (Maximum likelihood method) was employed, with a forced four-, five- and six-factor solutions, appearing as the most common models in the literature for this scale (cf Elias et al. 2017, Ristić et al. 2014, Hinić et al. 2013). The four-factor model explained $33 \%$ of the variance, anxious-cognitive items were placed under depressive, and anxious-somatic under cyclothymic factor. The five-factor model explained $36 \%$ of the variance, anxious-somatic items again fell under cyclothymic, while the cognitive factor was extracted as a single factor. Finally, the six-factor model explained $39.9 \%$ of the variance, in which items from the anxious scale were also clearly divided into the somatic and cognitive subscales (Table 2). This model showed best model fit indices $\left(\chi^{2} / \mathrm{df}=3.526 ; \mathrm{p}<0.01 ; \mathrm{GFI}=0.948 ; \mathrm{AGFI}=0.940\right.$; $\mathrm{CFI}=0.889$; $\mathrm{RMSEA}=0.035$; PCLOSE=1.000).

Cyclothymic factor was singled out as a dominant temperament type and explained $16.6 \%$ of the variance. Depressive temperament explained $7.6 \%$ of the variance, hyperthymic $5.0 \%$, and irritable temperament $4.2 \%$. Finally, in this study the anxious type was divided into anxious-cognitive ( $3.5 \%$ of the variance), and anxious-somatic (3.2\% of the variance).

Similarly to previous studies, two superfactors were extracted, explaining $60 \%$ of the total variance. The first, contained depressive, cyclothymic, irritable and both types of anxious temperaments and explained $42.6 \%$ of the variance, whereas the second with hyperthymic temperament explained $17.5 \%$ of the variance. The correlations between temperaments ranged from weak to moderate, with the highest positive correlations between the depressive, cyclothymic, and anxious scales (Table 3). 
Table 2. Adolescent TEMPS-A factor loadings

\begin{tabular}{|c|c|c|c|c|c|}
\hline & $\begin{array}{l}\text { Cyclo- } \\
\text { thymic }\end{array}$ & $\begin{array}{l}\text { Depres- } \\
\text { sive }\end{array}$ & $\begin{array}{l}\text { Hyper- } \\
\text { thymic }\end{array}$ & $\begin{array}{l}\text { Irrit } \\
\text { able }\end{array}$ & $\begin{array}{l}\text { Anxious- Anxious- } \\
\text { Cognitive Somatic }\end{array}$ \\
\hline 1. I get sudden changes in mood and energy & 0.591 & & & & \\
\hline 2. My mood often changes for no reason & 0.660 & & & & \\
\hline $\begin{array}{l}\text { 3. I am constantly being switched between lively } \\
\text { and listless }\end{array}$ & 0.631 & & & & \\
\hline $\begin{array}{l}\text { 4. Sometimes I go to bed feeling great, and wake up } \\
\text { in the morning feeling down }\end{array}$ & 0.504 & & & & \\
\hline $\begin{array}{l}\text { 5. My need for sleep varies a lot from just a few hours } \\
\text { to over } 9 \text { hours }\end{array}$ & 0.439 & & & & \\
\hline 6. I can be sad and happy at the same time & 0.456 & & & & \\
\hline $\begin{array}{l}\text { 7. I sometimes have problems to fall asleep for } \\
\text { no reason }\end{array}$ & 0.443 & & & & \\
\hline
\end{tabular}
no reason

14. I am by nature dissatisfied person 
Table 3. Correlation coefficients between the Adolescent TEMPS subscales

\begin{tabular}{|c|c|c|c|c|c|}
\hline & Cyclothymic & Hyperthymic & Irritable & Anx.Cog. & Anx.Som. \\
\hline Depressive & $0.399 * *$ & $-0.379 * *$ & $0.307 * *$ & $0.448 * *$ & $0.394 * *$ \\
\hline Cyclothymic & & $-0.147 * *$ & $0.381 * *$ & $0.326^{* *}$ & $0.430 * *$ \\
\hline Hyperthymic & $-0.147 * *$ & & -0.025 & $-0.202 * *$ & $-0.178 * *$ \\
\hline Irritable & $0.381 * *$ & -0.025 & & $0.219 * *$ & $0.279 * *$ \\
\hline Anx.Cognitive & $0.326 * *$ & $-0.202 * *$ & $0.219 * *$ & & $0.370 * *$ \\
\hline
\end{tabular}

Table 4. Basic results of the Adolescent TEMPS-A scale

\begin{tabular}{lccccccc}
\hline Temperaments & $\begin{array}{c}\text { Mean } \\
(\mathrm{StD})\end{array}$ & $\begin{array}{c}\text { Female } \\
\mathrm{M}(\mathrm{StD})\end{array}$ & $\begin{array}{c}\text { Male } \\
\mathrm{M}(\mathrm{StD})\end{array}$ & $\begin{array}{c}\text { Kolmogorov } \\
\text {-Smirnov }\end{array}$ & $\begin{array}{c}\text { Skewness/ } \\
\text { Kurtosis }\end{array}$ & $\alpha$ & rho \\
\hline Depressive & $0.23(0.24)$ & $0.26(0.25)$ & $0.20(0.22)$ & $0.221^{* *}$ & $1.048 / 0.409$ & 0.69 & 0.78 \\
Cyclothymic & $0.52(0.28)$ & $0.58(0.28)$ & $0.44(0.27)$ & $0.119^{* *}$ & $0.017 /-0.994$ & 0.66 & 0.81 \\
Hyperthymic & $0.74(0.24)$ & $0.72(0.24)$ & $0.77(0.22)$ & $0.195 * *$ & $-0.812 /-0.107$ & 0.68 & 0.91 \\
Irritable & $0.49(0.30)$ & $0.50(0.30)$ & $0.48(0.29)$ & $0.117^{* *}$ & $0.074 /-1.006$ & 0.71 & 0.87 \\
Anxious-Cognitive & $0.42(0.39)$ & $0.47(0.40)$ & $0.34(0.37)$ & $0.232^{* *}$ & $0.309 /-1.401$ & 0.70 & 0.81 \\
Anxious-Somatic & $0.36(0.31)$ & $0.44(0.32)$ & $0.27(0.28)$ & $0.196^{* *}$ & $0.456 /-0.855$ & 0.69 & 0.82 \\
\hline
\end{tabular}

$* * \mathrm{p}<0.01$

Table 5. Differences and correlations between demographic variables and TEMPS scale

\begin{tabular}{|c|c|c|c|c|c|c|}
\hline & Depressive & Cyclothymic & Hyperthymic & Irritable & Anx. Cog. & Anx. Som. \\
\hline Sex & $\mathrm{U}=-6.106^{* *}$ & $\mathrm{U}=-11.917 * *$ & $\mathrm{U}=5.744 * *$ & $\mathrm{U}=-1.112$ & $\mathrm{U}=-7.793 * *$ & $\mathrm{U}=-13.484^{* *}$ \\
\hline Av. mark & $\mathrm{rho}=0.081 *$ & $\mathrm{rho}=0.166^{* *}$ & $\mathrm{rho}=0.109 * *$ & $\mathrm{rho}=0.164 * *$ & $\mathrm{rho}=-0.042$ & $\mathrm{rho}=0.061 *$ \\
\hline Econ.status & $\mathrm{rho}=-0.186^{* *}$ & $\mathrm{rho}=-0.102 * *$ & $\mathrm{rho}=0.083 * *$ & $\mathrm{rho}=-0.009$ & $\mathrm{rho}=-0.124 * *$ & $\mathrm{rho}=-0.092 * *$ \\
\hline Region & $\mathrm{H}=9.55^{*}$ & $\mathrm{H}=8.70$ & $\mathrm{H}=40.22 * *$ & $\mathrm{H}=8.45$ & $\mathrm{H}=1.83$ & $\mathrm{H}=3.07$ \\
\hline
\end{tabular}

The final A-TEMPS-A scale showed good overall reliability, with internal consistency coefficient $\alpha=0.77$, average retest coefficient $\mathrm{rho}=0.78$ and SpearmanBrown coefficient of validity of 0.71 .

All the tested scores for both sex groups, except for hyperthymic temperament, deviated from normal distribution and showed a negatively skewed distribution (Table 4). The hyperthymic scores were skewed towards higher values.

\section{Temperaments and demographic characteristics}

The female participants had significantly higher scores on depressive, cyclothymic and both types of anxious temperaments, while male participants reported higher scores on hyperthymic (Table 5). We have not performed a correlation with age because all the subjects were 16 or 17 years old. The correlation with school achievement (average overall mark) was detected in some types of temperament (Table 5). However, the correlation was quite low, as it was with economic status. According to regions, no significant differences were detected, except for depressive temperament, where the scores in Kosovo and Metohia were the lowest, and in Vojvodina the highest. The same was true for hyperthymic temperament, where these differences were in reverse order (Vojvodina reported the lowest, Kosovo and Metohia the highest values). According to school types, differences follow the distribution of students according to sex; hence, these results will not be presented herein.

The mean values (Table 4) showed the highest values on hyperthymic temperament and the lowest on depressive, which tallies with the results of similar studies in non-clinical samples (cf Ristić et al. 2014). When these values are compared with the results in general population obtained upon the standardisation of the Serbian version of the scale (Ristic et al. 2014), significantly higher scores may be noticed in adolescents on all temperament types, from anxious-cognitive $(\mathrm{t}(2)=4.43 ; \mathrm{p}<0.001$; $\mathrm{d}=0.10)$ and somatic $(\mathrm{t}(2)=12.41 ; \mathrm{p}<0.001 ; \mathrm{d}=0.26)$, where the difference is the smallest, to cyclothymic $(\mathrm{t}(2)=30.52 ; \mathrm{p}<0.001 ; \mathrm{d}=0.68)$ and irritable $(\mathrm{t}(2)=32.58$; $\mathrm{p}<0.001 ; \mathrm{d}=0.70$ ), with the highest differences. The adolescents also showed higher values of average scores in comparison to the scores obtained in university student research in Serbia. These values are statistically higher on all temperament types, from irritable $(\mathrm{t}(2)=29.49$; $\mathrm{p}<0.001 ; \mathrm{d}=0.63)$ and cyclothymic $(\mathrm{t}(2)=25.66 ; \mathrm{p}<0.001$; $\mathrm{d}=0.57)$, to hyperthymic $(\mathrm{t}(2)=19.96 ; \mathrm{p}<0.001 ; \mathrm{d}=0.43)$ and depressive $(\mathrm{t}(2)=15.97 ; \mathrm{p}<0.001 ; \mathrm{d}=0.33)$, except for anxious $(\mathrm{t}=3.68)$, which in the said research was not divided into two subfactors. 


\section{DISCUSSION}

The main finding of the present study is that affective temperaments can be reliably identified in adolescent population with this version of the scale. The final version of the scale had 36 items, clustered around depressive (7), cyclothymic (7), hyperthymic (8), irritable (7), anxiouscognitive (3), anxious-somatic (4). Since the number of items on subscales is not the same, we propose that the average value for each subscale should be computed, so that the gathered values could be comparable.

As with many other previous studies conducted in younger and adult samples (Woodruff et al. 2011, Figueira et al. 2010, Rózsa et al. 2008, Blöink et al. 2005), the results of the current study have shown expected strong (positive) correlations between depressive, cyclothymic and both types of anxious temperament, and cyclothymic and both types of anxious temperament. Apart from that, a positive correlation between irritable and cyclothymic temperament was confirmed in these studies, and a negative between hyperthymic and all other temperament types. Such a link between temperament types has clinical implications too. Therefore, some authors maintain that hyperthymic temperament could be a protective factor against suicide among affective patients (Vázquez et al. 2010). Likewise, in a study where a number of subjects included adolescents (Guerreiro et al. 2013), hyperthymic temperament was the only dimension of temperament which did not have significant association with self-harm.

The mean values (Table 4) showed the highest values on hyperthymic temperament. In the two previous studies which included adolescent samples (Placidi et al. 1998a, Placidi et al. 1998b), the highest score was also detected on hyperthymic temperament. The distribution of other scores corresponds with our results to a certain extent. A temperament type following hyperthymic in high scores was cyclothymic, which tallies with the results reported in the literature, underlining that cyclothymia appears in early adolescence (Akiskal 1995).

The participants reported the lowest scores on depressive temperament, which may be interpreted to mean that depressive temperament is not fully developed in that period of life, and that it can be conditioned by specific cultural features of the environment surrounding the participants. The most significant factor with regard to depression in younger children is related to sadness, lack of enjoyment, feelings of being unloved, while in adolescents the symptoms are grouped under a general depressive-anxiety factor, which also includes worries, irritability and some somatic symptoms (Poli et al. 2001). High emotionality, being a temperament feature, is closely connected with the risk of depression and anxiety in adolescents (Masi et al. 2003), which may be the reason for joint covariance of these traits and overlapping of factors in the original five-factor model of the TEMPS-A scale.

Gender differences have also been found in the present study. Namely, girls had significantly higher scores on depressive, cyclothymic and both types of anxious temperament, while boys had higher scores on hyperthymic temperament. Such results correspond with earlier research in adolescents (Placidi et al. 1998a), and previous research on student population, both in Serbia (Hinić et al. 2013) and worldwide (Vázquez et al. 2012, Woodruff et al. 2011). These results may be interpreted in view of the following statement: cyclothymic temperament is more frequent in females and hyperthymia might be more of a male attribute, especially in juvenile years (Akiskal \& Akiskal 2005). In a similar vein, the results tend to support the hypothesis on the evolutionary function of anxious-depressive traits in women (Akiskal \& Akiskal 2005) as well as findings supporting the idea that the prevalence of depressive disorders in females does not start to be evident before adolescence (Poli et al. 2001). Bearing in mind the fact that recent studies indicate that certain brain structures of boys and girls are differently developed under the influence of sex hormones, the maturation process may partly have an impact on the mentioned gender differences (Herting et al. 2015).

In studies that used the Cloninger's model (Zohar et al. 2018; Cloninger et al. 1994), it is reported that girls have lower scores in novelty seeking and higher in harm avoidance. Earlier findings show that the harm avoidance dimension is negatively associated with hyperthymic temperament scores, and positively with both depressive and anxious temperament scores (RisticIgnjatovic et al. 2014, Rozsa et al. 2008). Therefore, those findings correspond to our results that girls had higher scores on depressive and anxiety temperament, and lower on hyperimetic than boys.

It is interesting to note that all the scores reported in the current study are significantly higher than those reported in university students (Hinić et al. 2013), and general population (Ristić et al. 2014). Similar results were reported in some other studies (Guerreiro et al. 2013, Placidia et al. 1998b). One of the possible explanations would be that the temperament traits determine a young person's responses to the environment to the greatest extent (Zentner \& Shiner 2012), whereas in later stages of life these responses are conditioned by character traits, which are formed in the course of personality maturation under the influence of society and social norms. The mere temperament traits are considered to be the outcome of the maturation of biologically determined neurological structures (Shiner \& Caspi 2003), which are under the impact of environmental experiences (Kochman et al. 2005) and social interactions. This is in accordance with previous studies which show that an increase in stability occurs with age (Vázquez et al. 2012, Sanson et al. 1991); thus, there is clear stability of temperaments throughout adulthood (Kawamura et al. 2010), and instability in childhood, particularly in adolescence (Placidi et al. 1998b).

The adolescents in the present study have shown the greatest difference in scores on irritable and cyclothymic temperaments in comparison to general and university student population, which also speaks in 
favour of potential influence of social norms and social interactions during life, where newly formed personality traits have a control function over emotional responses. It was also difficult for the subjects to respond honestly to some of the items since these may be found too intimate in this developmental stage (eg all the items relating to sexual behaviour, love etc) or impose a high social pressure on them (if they are organised, hardworking etc; all the items relating to alcohol consumption or consumption of other substances; if they tease other people; and even the item referring to the fact whether they swear a lot was problematic). The existing research, especially studies conducted in university students, has shown similar problems with culturally "coloured" items (Hinić et al. 2013, Dolenc et al. 2013).

Major strengths of this study include a large sample size, representative of different regions in Serbia, as well as different socioeconomic status. However, due to the specific design of the study, the subjects were not chosen according to the health criterion, which represents a limitation of the present study.

\section{CONCLUSIONS}

The final version of the A-TEMPS-A scale has shown good psychometric properties in this understudied population. Furthermore, the results on all the subscales show increased values in comparison to adult population, which may be the reason why it would be advisable to monitor the stability of temperament in some prospective study.

Although external validation with some personality scales, eg TCI-R scale (Dzamonja-Ignjatovic et al. 2010), has already been performed in adult population in Serbia, an excellent accompaniment to this scale would be some personality inventory, adapted to younger populations.

\section{Acknowledgements: None.}

\section{Conflict of interest: None to declare.}

\section{Contribution of individual authors:}

Jović Jelena - data collection, design of the study, manuscript writing, literature searches and analyses, interpretation of data;

Darko Hinić - statistical analysis, manuscript writing, literature searches and analyses, interpretation of data;

Aleksandar Ćorac - data collection, interpretation of data;

Hagop S. Akiskal - design of the study, literature searches and analyses, interpretation of data;

Kareen Akiskal \& Icro Maremmani - design of the study, literature searches and analyses;

Dina Popović - literature searches and analyses, interpretation of data, manuscript writing;

Dragana Ristić-Ignjatović - data collection, design of the study, manuscript writing.

\section{References}

1. Akiskal HS: Developmental pathways to bipolarity: Are juvenile-onset depressions pre-bipolar? J Am Acad Child Adolesc Psychiatry 1995; 34:754-63

2. Akiskal KK\& Akiskal HS: The theoretical underpinnings of affective temperaments: implications for evolutionary foundations of bipolar disorder and human nature. $J$ Affect Disord 2005; 85:231-39

3. Baldessarini RJ, Vázquez GH \& Tondo L: Affective temperaments and suicidal ideation and behavior in mood and anxiety disorder patients. J Affect Disord 2016; 198:78-82

4. Blöink R, Brieger P, Akiskal HS \& Marneros A: Factorial structure and internal consistency of the German TEMPSA scale: validation against the NEO-FFI questionnaire. $J$ Affect Disord 2005; 85:77-83

5. Cloninger CR, Przybeck TR \& Svrakic DM: The Temperament and Character Inventory (TCI): a guide to its development and use. St. Louis, MO: Center for Psychobiology of Personality, Washington University, 1994

6. Dolenc B, Sprah L, Dernovšek MZ, Akiskal K \& Akiskal HS: Psychometric properties of the Slovenian version of temperament evaluation of Memphis, Pisa, Paris, and San DiegoAutoquestionnaire (TEMPS-A): temperament profiles in Slovenian university students. J Affect Disord 2013; 144:253-62

7. Dzamonja-Ignjatovic T, Svrakic DM, Svrakic N, Jovanovic $M D$, Cloninger RC: Cross-cultural validation of the revised Temperament and Character Inventory: Serbian data. Compr Psychiatry 2010; 51:649-655

8. Figueira ML, Caeiro L, Ferro A, Cordeiro R, Duarte PM, Akiskal HS \& Akiskal KK: Temperament in Portuguese university students as measured by TEMPS-A: implications for professional choice. J Affect Disord 2010; 123:30-35

9. Guerreiro DF, Sampaio D, Rihmer Z, Gonda $X$ \& Figueira ML: Affective temperaments and self-harm in adolescents: A cross-sectional study from a community sample. J Affect Disord 2013; 151:891-98

10. Herting MM, Gautam P, Spielberg JM, Dahl RE \& Sowell ER: A longitudinal study: changes in cortical thickness and surface area during pubertal maturation. PLOS One 2015; 10:e0119774

11. Hinić D, Akiskal SH, Akiskal KK, Jović J \& Ristić-Ignjatović D: Validation of the TEMPS-A in university student population in Serbia. J Affect Disord 2013; 149:146-51

12. Kawamura Y, Akiyama T, Shimada T, Minato T, Umekage T, Noda Y, Ukawa K, Hashidume C, Sakai Y, Otowa T, Sasaki T \& Akiskal HS: Six-year stability of affective temperaments as measured by TEMPS-A. Psychopathol 2010; 43:240-47

13. Kesebir S, Gündoğar D, Küçüksubaşı Y \& Tatlddil Yaylacı $E$ : The relation between affective temperament and resilience in depression: a controlled study. J Affect Disord 2013; 148:352-56

14. Kochman FJ, Hantouche EG, Ferrari P, Lancrenon S, Bayart D \& Akiskal HS: Cyclothymic temperament as a prospective predictor of bipolarity and suicidality in children and adolescents with major depressive disorder. $J$ Affect Disord 2005; 85:181-89

15. Elias LR, Köhler CA, Stubbs B, Maciel BR, Cavalcante LM, Vale AM, Gonda X, Quevedo J, Hyphantis TN, Soares JC, Vieta $E$ \& Carvalho $A F$ : Measuring affective temperaments: a systematic review of validation studies of the Temperament Evaluation in Memphis Pisa and San Diego (TEMPS) instruments. J Affect Disord 2017; 212:25-37

16. Maremmani I, Dell'Osso L, Rovai L, Arduino G, Montagnari A, Abbenante D, Popovic D, Maremmani AG, Perugi 
G, Akiskal $K \&$ Akiskal HS: Discriminant and convergent validity of TEMPS-A[P] correlation with MMPI and the emotional-affective state following a stressful situation. $J$ Affect Disord 2011; 129:27-33

17. Masi G, Mucci M, Favilla L, Brovedani P, Millepiedi $S$ \& Perugi G: Temperament in adolescents with anxiety and depressive disorders and in their families. Child Psychiat Hum Dev 2003; 33:245-59

18. MPNTR - Ministry of Education, Science and Technological Development: Secondary education - List of secondary schools. Ministry of Education, Science and Technological Development, Republic of Serbia. 2015; Available from: http://opendata.mpn.gov.rs/get.php?dataset $=$ skole\&lang $=s r$ \&term $=x l s$

19. Nolen-Hoeksema S: Gender differences in depression. In Gotlib IH \& Hammen CL (eds): Handbook of Depression, 492-509. New York, NY: Guilford Press, 2002

20. Placidi GF, Signoretta S, Liguori A, Gervasi R, Maremmani I \& Akiskal HS: The semi-structured affective temperament interview (TEMPS-I) Reliability and psychometric properties in 1010 14-26-year-old students. J Affect Disord $1998 a ; 47: 1-10$

21. Placidi GF, Maremmani I, Signoretta S, Liguori A \& Akiskal HS: A prospective study of stability and change over 2 years of affective temperaments in 14-18 year-old Italian high school students. J Affect Disord 1998b; 51:199-208

22. Poli P, Sbrana B, Marcheschi M \& Masi G: Self-Reported Depressive Symptoms in a School Sample of Italian Children and Adolescents. Child Psychiat Hum Dev 2001; 33:209-26

23. Pompili M, Rihmer Z, Akiskal HS, Innamorati M, Iliceto $P$, Akiskal KK, Lester D, Narciso V, Ferracuti S, Tatarelli $R$, DePisa $E \&$ G Girardi P: Temperament and personality dimensions in suicidal and nonsuicidal psychiatric inpatients. Psychopathol 2008; 41:313-21

24. Rihmer Z, Akiskal KK, Rihmer A \& Akiskal HS: Current research on affective temperaments. Curr Opin Psychiatry 2010; 23:12-18

25. Ristić-Ignjatović D: Developmental psychiatry. In ĐukićDejanović S (ed): Psychiatry, 465-491. Kragujevac, Serbia: Faculty of Medical Sciences, 2011

26. Ristić-Ignjatović D, Hinić D, Bessonov D, Akiskal SH, Akiskal KK \& Ristic B: Towards validation of the short TEMPS-A in non-clinical adult population in Serbia. $J$ Affect Disord 2014; 164:43-49

27. Rovai L, Leonardi A, Bacciardi S, Maremmani AG, Rugani $F$, dell'Osso L, Akiskal K, Akiskal HS \& Maremmani I: Discriminant and convergent validity of TEMPS-A[P]. Correlation with Occupational Personality Questionnaire (OPQ32) during a stressful situation. J Affect Disord 2013; 146:142-45

28. Rózsa S, Rihmer Z, Gonda X, Szili I, Rihmer A, Kö N, Németh A, Pestality P, Bagdy G, Alhassoon O, Akiskal KK \& Akiskal HS: A study of affective temperaments in Hungary: Internal consistency and concurrent validity of the TEMPS-A against the TCI and NEO-PI-R. J Affect Disord 2008; 106:45-53
29. Sanson A, Oberklaid F, Pedlow R \& Prior M: Risk indicators: assessment of infancy predictors of pre-school behavioral maladjustment. Child Psychol Psychiatry 1991; 32:609-26

30. Schuch B: Social anxiety in childhood and youth. Psychiatr Danub 2009; 21:549-54

31. Shiner $R \&$ \& Caspi A: Personality differences in childhood and adolescence: measurement, development, and consequences. J Child Psychol Psychiatry 2003; 44:2-32

32. Skala K, Kapusta ND, Schlaff G, Unseld M, Erfurth A, Lesch OM, Walter H, Akiskal KK \& Akiskal HS: Suicidal ideation and temperament: an investigation among college students. J Affect Disord 2012; 141:399-405

33. Signoretta S, Maremmani I, Liguori A, Perugi $G \&$ Akiskal HS: Affective temperament traits measured by TEMPS-I and emotional-behavioral problems in clinically-well children, adolescents, and young adults. J Affect Disord 2005; 85:169-80

34. SORS - Statistical Office of the Republic of Serbia: Statistical Pocketbook of the Republic of Serbia 2015. Belgrade. Available from: http://webrzs.stat.gov.rs/WebSite/repository/documents/00/0 1/71/83/Statisticki_kalendar_Republike_Srbije_2015.pdf

35. Tanabe S, Terao T, Shiotsuki I, Kanehisa M, Ishii K, Shigemitsu $O$, Fujiki $M \&$ Hoaki $N$ : Anxious temperament as a risk factor of suicide attempt. Compr Psychiatry 2016; 68: $72-77$

36. Tavormina G: The temperaments and their role in early diagnosis of bipolar spectrum disorders. Psychiatr Danub 2010; 22(Suppl. 1):15-17

37. Vázquez GH, Gonda X, Zaratiegui R, Lorenzo LS, Akiskal K \& Akiskal HS: Hyperthymic temperament may protect against suicidal ideation. J Affect Disord 2010; 127:38-42

38. Vázquez GH, Tondo L, Mazzarini L \& Gonda X: Affective temperaments in general population: $A$ review and combined analysis from national studies. $J$ Affect Disord 2012; 139:18-22

39. Vellante M, Zucca G, Preti A, Sisti D, Rocchi MB, Akiskal $K K \&$ Akiskal HS: Creativity and affective temperaments in non-clinical professional artists: an empirical psychometric investigation. J Affect Disord 2011; 135:28-36

40. WHO - World Health Organization: WHO/UNAIDS launch new standards to improve adolescent care. 2015; Available from: http://www.who.int/mediacentre/news/releases/ 2015/health-standards-adolescents/en/

41. Woodruff E, Genaro LT, Landeira-Fernandez J, Cheniaux E, Laks J, Jean-Louis G, Nardi AE, Versiani MC, Akiskal $H S \&$ Mendlowicz MV: Validation of the Brazilian brief version of the temperament auto-questionnaire TEMPS-A: The brief TEMPS-Rio de Janeiro. J Affect Disord 2011; 134:65-76

42. Zentner $M$ \& Shiner RL: Handbook of Temperament. Guilford Press, New York, 2012

43. Zohar AH, Zwir I, Wang J, Cloninger CR \& Anokhin AP: The development of temperament and character during adolescence: The processes and phases of change. Dev Psychopathol 2018; 1-17

Correspondence:

Prof. Darko Hinić, PhD

Faculty of Science, Faculty of Philology and Arts, University of Kragujevac

Radoja Domanovića 12, 34000 Kragujevac, Serbia

E-mail:dhinic@kg.ac.rs 